\title{
Pitch Angle Control for Variable Speed Wind Turbines
}

\author{
Mouna BEN SMIDA, Anis.SAKLY \\ Research Unit: Industrial systems study and renewable energy (ESIER), \\ Key the National Engineering School of Monastir (ENIM), \\ University of Monastir, Av. Ibn El Jazzar Skanes (5019), TUNISIA.
}

\begin{abstract}
Pitch control is a practical technique for power regulation above the rated wind speed it is considered as the most efficient and popular power control method. As conventional pitch control usually use PI controller, the mathematical model of the system should be known well.This paper deals with the operation and the control of the direct driven permanent magnet synchronous generator (PMSG).
\end{abstract}

Different conventional strategies of pitch angle control are described and validated through simulation results under MatlabISimulink.

Keywords - variable-speed wind turbine; MPPT; pitch control; PMSG.

\section{Nomenclature -}

$\begin{array}{ll}\text { PMSG } & \text { Permanent magnet synchronous generator } \\ \text { HAWT } & \text { Horizontal-axis wind turbines } \\ \text { VAWT } & \text { Vertical axis wind turbines } \\ \text { TSR } & \text { Tip speed ratio } \\ \text { MPPT } & \text { Maximum Power Point Tracking } \\ \text { PWM } & \text { Pulse width modulation } \\ \text { PI } & \text { Proportional integral }\end{array}$

\section{INTRODUCTION}

Traditional energy resources, especially from fossil origins, will break off in the following few decades, which predict an energy shortage in the world. In addition, the energy consumption, in its various forms, increased in an exponential way. To satisfy these needs, it was necessary to solve this problem. Actually, there was a simple way to do so, since there were inexhaustible renewable energy resources, which can be easily and properly exploited [1-3]. Nevertheless, being neglected for a long time, power extraction techniques of these resources requires more researches and developments aiming to make the manufacturing costs reliable and lower and to increase the energy efficiency [4-5].

In this general context, this study was interested in the wind energy which seems to be one of the most promising energies with a very high rate growth in the world. Today, the wind power has become a reality with the increase of the installed power all over the world a significant proportion of this type of energy is available in windy areas.

Recently, pitch-adjusting variable-speed wind turbines have become the dominating type of installed wind turbines.Pitch angle control method is a basic approach to improve the performance of the power generation system including different types of wind turbines. Although a wind turbine can be built in either a vertical-axis or horizontal-axis configuration, we focus on horizontal-axis wind turbines (HAWTs) because they dominate the utility-scale wind turbine market. At the utility scale, HAWTs have aerodynamic and practical advantages [6]. Smaller vertical axis wind turbines (VAWTs) are more likely to use passive rather than active control strategies. In fact, generally for vertical axis wind turbine, which consists of several blades rotating about axis in parallel direction, the cycloid blade system and the individual active blade control system are adopted.

Both methods are variable pitch system. For cycloid wind turbine, aerodynamic analysis is carried out by changing pitch angle and phase angle based on the cycloid motion according to the change of wind speed and wind direction. And for more efficient wind turbine, individual pitch angle control of each blade is obtained by maximizing the tangential force in each rotating blade at the specific rotating position, optimal.

Therefore, generally for the variable-speed wind turbines two controllers are used. Below rated value, in low wind speed, the speed controller can continuously adjust the rotor speed to maintain the tip speed ratio constant at the level which gives the maximum power coefficient, so the efficiency of the turbine will be significantly increased. Pitch angle regulation is necessary in conditions above the rated wind speed when the rotational speed is kept constant which can have a dramatic effect on the power output. The purpose of the pitch angle control might be expressed as follows [7-8]: 
- Optimizing the wind turbine power output. Below rated wind speed, the pitch setting should be at its optimum value to give maximum power.

- Preventing the mechanical power input to beat the design limits. Above rated wind speed, pitch angle control provides an effective method of regulating the aerodynamic power and loads produced by the rotor.

- Minimizing fatigue loads of the turbine mechanical component. It is clear that the action of the control system can have a major impact on the loads experienced by the turbine. The design of the controller must take into account the effect on loads, and the controller should ensure that excessive loads will not result from the control action. It is possible to go further than this, and explicitly design the controller with the reduction of certain fatigue loads as an additional objective.

In this paper, conventional pitch angle control strategy in which various controlling variables may be used is discussed.

\section{WIND TURBINE MODELING}

In order to simulate the behavior of the wind turbine, it is necessary to determine the torque exerted on its shaft.The mechanical power extracted from the wind turbine is expressed by [9-10]:

$$
P_{w}=\frac{1}{2} r p R^{2} V_{w}^{3} C_{p}(1, b)
$$

The power coefficient $\mathrm{Cp}$ depends on the pitch angle of rotor blades $\beta$ and the tip speed ratio (TSR) $\lambda$, with [11]:

$$
C_{p}(\lambda, \beta)=0.53\left[\frac{151}{\lambda_{i}}-0.58 \beta-0.002 \beta^{2.14}-13.2\right] \times \exp \left(\frac{-18.4}{\lambda_{i}}\right)
$$

Where:

$$
\begin{aligned}
& I_{i}=\frac{1}{\frac{1}{1-0.02 b}-\frac{0.003}{b^{3}+1}} \\
& I=\frac{R W}{V_{w}}
\end{aligned}
$$

The turbine torque is then defined as the ratio of the mechanical power to the rotational speed:
$T_{m}=\frac{P_{w}}{W}$

The mechanical speed of the turbine is determined from the fundamental equation of the dynamics as:

$J \frac{d W}{d t}=T_{m}-T_{e m}-f W$

The wind turbine speed is controlled in order to extract the maximum power from the wind. According to the Betz theory, the maximum power extractable from a wind turbine is $59.3 \%$ of the available wind power, which corresponds to the Betz limit with a power coefficient of 0.593 [12].

For the wind turbine modeled in this study, the curve of $\mathrm{Cp}$ versus $\lambda$ with ${ }^{b}=0$, represented in Fig. 1 , shows an optimum value of the TSR $\left(l_{\text {opt }}=8\right.$ ) corresponding to a maximum value of the power coefficient $($ Cpmax $=0.473$ ).

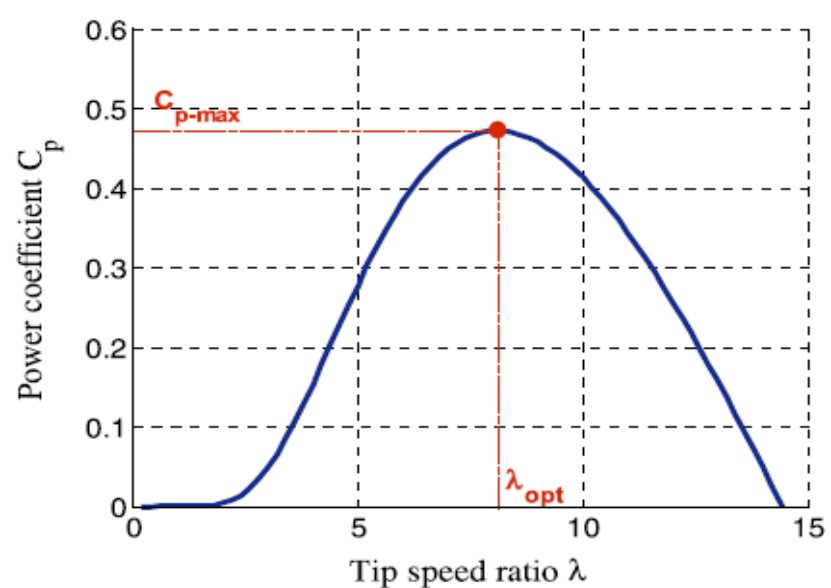

Fig .1. Cp versus ${ }^{l}$ curve

\section{A. Control of the Wind Generator}

The control of the generator power is obtained by the control of the PMSG electromagnetic torque Tem. The role of the pitch control system is to limit the rotational speed of the shaft, the reference electromagnetic torque Tem-ref, can be developed in this method [13]: The strategy of an operating at maximum power, goals to develop the turbine aerodynamic output, aiming to extract the maximum of wind power derived when the turbine operates at maximum power coefficient. 
Equation 7 gives the expression of the maximum power obtained using the Maximum Power Point Tracking (MPPT) strategy which adjust automatically the ratio speed at its optimum value , $1_{\text {opt }}$, in order to attain the maximum power coefficient Cpmax, the equation below indicates the relationship between turbine power and turbine speed at maximum power. When regulating the system under the specification of maximum power, it must be considered that turbine power must never be upper than generator rated power. The output power must be limited when generator rated power is attained at rated wind speed.

$$
\begin{aligned}
P_{M P P T} & =K_{o p t} \Omega^{3} \\
K_{o p t} & =\frac{1}{2} \frac{r p R^{5} C_{p \max }}{I_{o p t}^{3}}
\end{aligned}
$$

In the case of high wind, it is necessary to limit the rotational speed to avoid the damage of the turbine and the electric machine. This limitation is obtained by the control of the pitch angle $\beta$.

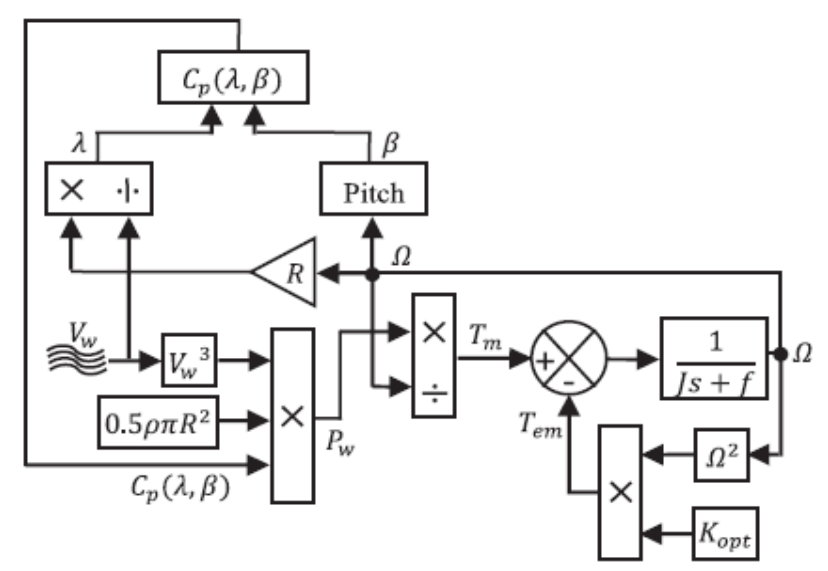

Fig .2. Turbine model

\section{B. Wind Turbine Operating Regions}

The Typical power control regions of wind turbine are shown in Figure 3. Three wind speeds are considered as limits of this division, the cut-in wind speed vcut-in, the rated wind speed vrated and the cut-out wind speed vcut-out. For the wind turbine model considered in this study the values of vcut-in, vrated and vcut-out respectively are $6 \mathrm{~m} / \mathrm{s}, 10 \mathrm{~m} / \mathrm{sand} 13 \mathrm{~m} / \mathrm{s}$. In region I, the wind turbine is at stop state and the pitch angle usually is set $1090^{\circ}$. In the partial load region, region II, the wind speed is limited between vcut-in and vrated. The main objective of the control in this region is maximizing power generated by the wind turbine. The principle control objective in the full load region, region III, is maintaining the generator power $P_{g}$ around the rated generator power $P_{g, \text { rated }}$.

In fact, in the case of high wind, it is necessary to limit the rotational speed to avoid the damage of the turbine and the electric machine. This limitation is obtained by the control of the pitch angle $b$.In region IV where the wind speed is upper than vcut-out, the wind turbine must be shut down in order to protect wind turbine against the stresses and fatigue damages. In this case, the pitch angle usually is set to $90^{\circ}$ and power generation is stopped. The focus of this paper is on full load region (region III) to design an optimal pitch controller.

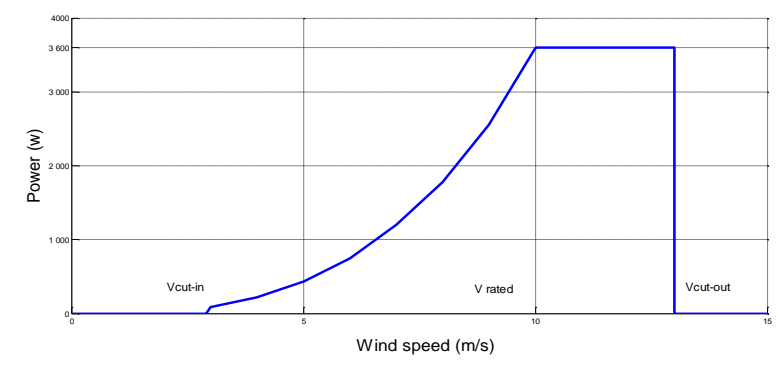

Fig .3. Wind Turbine operating regions

\section{PITCH ANGLE CONTROL}

The pitch control method is a basic approach for controlling the rotational speed of wind turbine. The conventional blade pitch angle control strategies are developed in this part. The pitch angle reference $b_{\text {ref }}$, is controlled by the input values, which may be as follows:

- Wind speed, as shown in Fig. 5(a). Perfectly, the pitch angle reference can be illustrated from the curve of the pitch angle versus wind speed, as shown in Fig.3. The direct measure of the wind speed makes this control strategy simple; however this is not a pertinent procedure, because it is difficult to measure the wind speed precisely.In fact, when the rotor speed exceeds the maximum rotor speed of turbine $\Omega$ tn, the pitch angle is increased to reduce the turbine torque $\mathrm{Ct}$. 


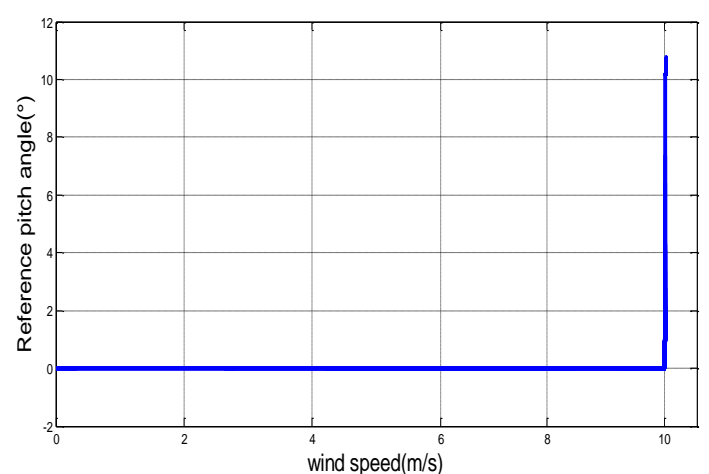

Fig .4. Reference Pitch angle

- Generator rotor speed, as shown in Fig. 5(b). The controlling rotor speed is compared with its reference. The error signal is then sent to the $\mathrm{PI}$ controller and produces the reference value of the pitch angle.

- Generator power, as shown in Fig. 5(c). The error signal of the generator power is sent to a $\mathrm{PI}$ controller. The PI controller produces the reference pitch angle $b_{r e f}$.

For variable-speed wind turbines, a mechanical actuator is generally used to adjust the pitch angle of the blades in order to decrease the power coefficient $\mathrm{Cp}$ and maintain the power at its rated value. By linearization of the model to order 1 [14-16], the torque has been considered proportional to rotational speed of the turbine. The control strategy implemented is as follows:

$$
\left\{\begin{array}{l}
\beta_{r e f}=\beta_{0}=0 \quad \text { for } 0<\Omega_{t}<\Omega_{t n} \\
\beta_{r e f}=\frac{\Delta \beta}{\Delta \Omega}\left(\Omega_{t}-\Omega_{t n}\right)+\beta_{0} \quad \text { for } \Omega_{t}>\Omega_{t n}
\end{array}\right.
$$

With is the initial pitch angle (optimal value) and $(\mathrm{rad} / \mathrm{s})$ is the nominal mechanical turbine speed. Taking into account the blades orientation system which can be hydraulic or electric type, a transfer function of the first order is introduced in order to control the position of the blades according to a reference.

$$
b=\frac{1}{1+t_{b} s} b_{r e f}
$$

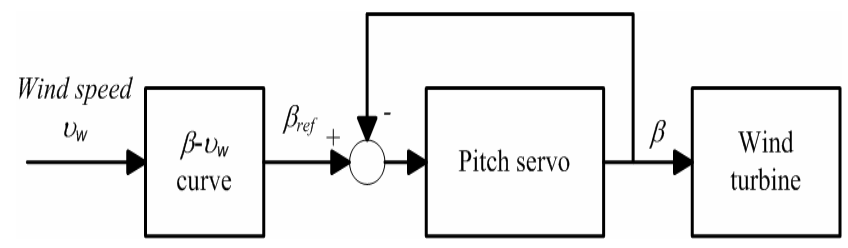

(a)

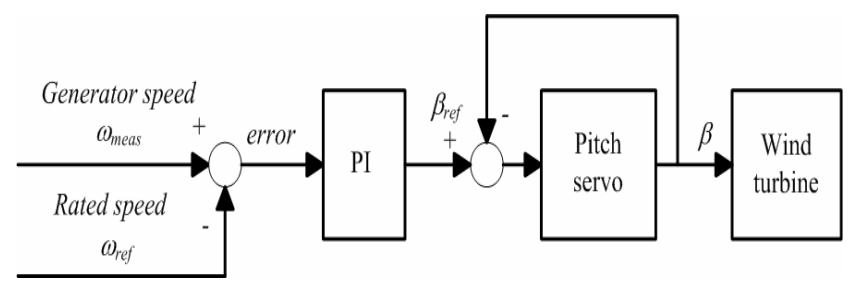

(b)

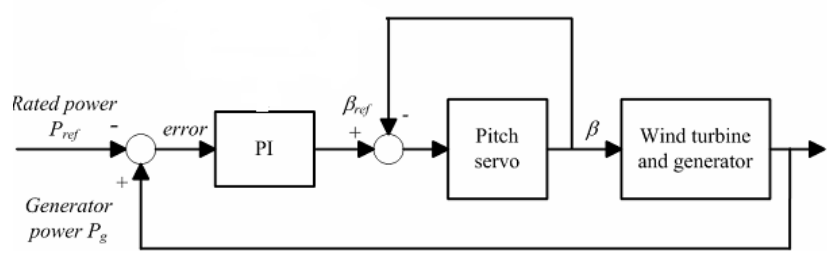

(c)

Fig .5. Pitch control strategy.(a) Wind speed; (b) generator rotor speed; (c) generator power

\section{PERMANENT- MAGNETIC SYNCHRONOUS GENERATOR AND RECTIFIER}

\section{A. Modeling of the PMSG}

In this study a PMSG Park model is used, only the fundamental harmonic of the flux distribution in the airgap of the machine is considered and the homopolar component is neglected, so the theory of the space vector gives the dynamic equations of the stator currents as follows:

$$
\left\{\begin{array}{l}
\frac{d i_{s d}}{d t}=\frac{1}{L_{s}}\left(v_{s d}-R_{s} i_{s d}+L_{s} p \Omega_{t} i_{s q}\right) \\
\frac{d i_{s q}}{d t}=\frac{1}{L_{s}}\left(v_{s q}-R_{s} i_{s q}-L_{s} p \Omega_{t} i_{s d}-p \Omega_{t} \varphi\right)
\end{array}\right.
$$

Where the phase resistance of the stator winding $(\Omega)$, the stator cyclic inductance $(H), \varphi$ is is the flux of the permanent magnetic $(\mathrm{Wb}), v_{s d}$ and $v_{s q}$ are the d-q components of the stator voltages respectively (V), $i_{s d}$ and $i_{s q}$ are the $\mathrm{d}-\mathrm{q}$ components of the stator currents respectively (A), and finally $p$ is the number 
of pairs of poles The electromagnetic torque is given by:

$$
C_{e m}=p \varphi i_{s q}
$$

\section{B. Modeling of the Rectifier}

For the dynamic model of the system, we will divide the study of the converter to three parts: the alternative part, the discontinuous part which is composed by switches and the DC side. In this context, the function of switches is to establish a connection between the AC side and the DC bus; these switches are complementary, their state is defined by the following function:

$S=\left\{\begin{array}{ll}+1 \\ -1\end{array}\right.$ for $\mathrm{S}=\mathrm{a}, \mathrm{b}, \mathrm{c}$

Then, the input phase voltages and the output current may be written in function of $\mathrm{Sj}$, Udc and input currents ia, ib, ic.

$$
i_{a}+i_{b}+i_{c}=0
$$

The phase between the input PWM rectifier voltages can be described by:

$$
\begin{aligned}
& U_{S a b}=\left(S_{a}-S_{b}\right) \cdot U_{D C} \\
& U_{S b c}=\left(S_{b}-S_{c}\right) \cdot U_{D C} \\
& U_{S c a}=\left(S_{c}-S_{a}\right) \cdot U_{D C}
\end{aligned}
$$

The voltage equations of the system can be written as follows:

$$
\left[\begin{array}{l}
e_{a} \\
e_{b} \\
e_{b}
\end{array}\right]=R \cdot\left[\begin{array}{l}
i_{a} \\
i_{b} \\
i_{c}
\end{array}\right]+L \cdot \frac{d}{d t}\left[\begin{array}{c}
i_{a} \\
i_{b} \\
i_{c}
\end{array}\right]+\left[\begin{array}{c}
U_{S a} \\
U_{S b} \\
U_{S c}
\end{array}\right]
$$

Avec:

$$
\begin{aligned}
& U_{S a}=\frac{2 S_{a}-S_{b}-S_{c}}{3} \cdot U_{D C} \\
& U_{S b}=\frac{2 S_{b}-S_{a}-S_{c}}{3} \cdot U_{D C} \\
& U_{S c}=\frac{2 S_{c}-S_{a}-S_{b}}{3} \cdot U_{D C}
\end{aligned}
$$

Finally, we deduce the equation coupling between $A C$ and DC sides by:

$$
C \frac{d U_{D c}}{d t}=S_{a} i_{a}+S_{b} i_{b}+S_{c} i_{c}
$$

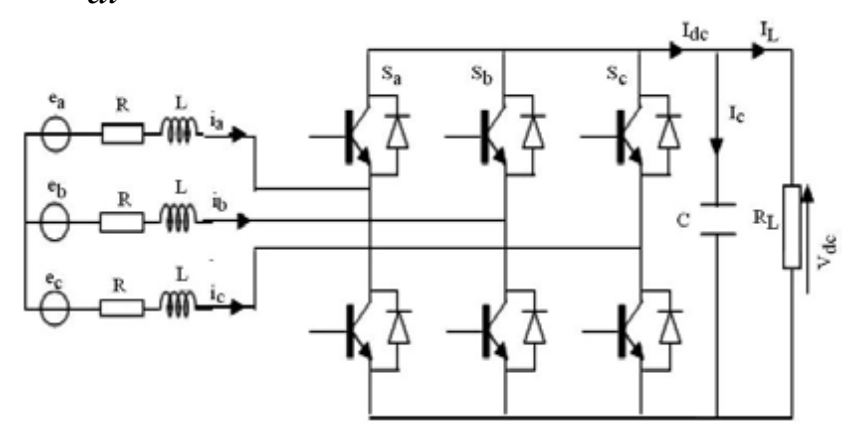

Fig .6. Diagram of MSAP- PWM Rectifier

\section{Control}

For variable-speed wind turbine, the maximum power is a cubic function of rotational speed. the development of the generator torque is based on the stator q-axis current component, but a freedom degree remains to set direct current. In order to minimize current for a given torque, and therefore, minimize resistive losses the direct-axis current component can be set at zero [17]. Thus, the control of the generator torque depends directly of the quadrature current component. The schematic diagram of the control loops of the permanent-magnet generator-side converter is illustrated on Fig. 7.The required $d-q$ components of the rectifier voltage vector are determinate from two proportional plus integral (PI) current controllers: the first one is controlling the $d$-axis component of the current and the other one is controlling the q-axis component. In order to improve the dynamic response, compensation terms are added.The control requires the measurement of the stator currents, dc voltage, and rotor position.

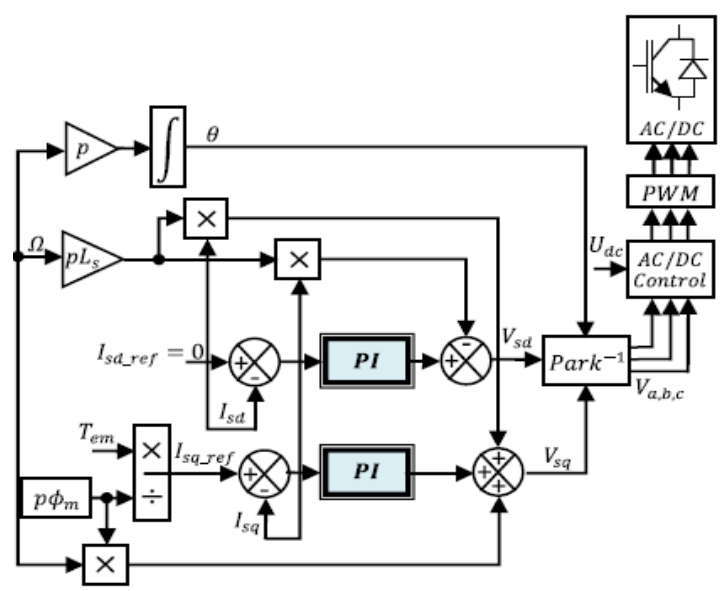

Fig .7. PMSG and converter control 


\section{Simulation Results and Discussion}

Pitch angle control systems of the wind turbine were simulated using MATLAB/SIMULINK tool to test the control strategy and evaluate the performance of the system. The wind model is necessary to obtain realistic simulations of the power control of the wind turbines [18]. During $300 \mathrm{~s}$, we have applied to the wind turbine model a variable wind profile between 6 and $12 \mathrm{~m} / \mathrm{s}$ with an average value of $10 \mathrm{~m} / \mathrm{s}$. This sequence is obtained by adding a turbulent component to a slowly varying signal represented in Fig.8.

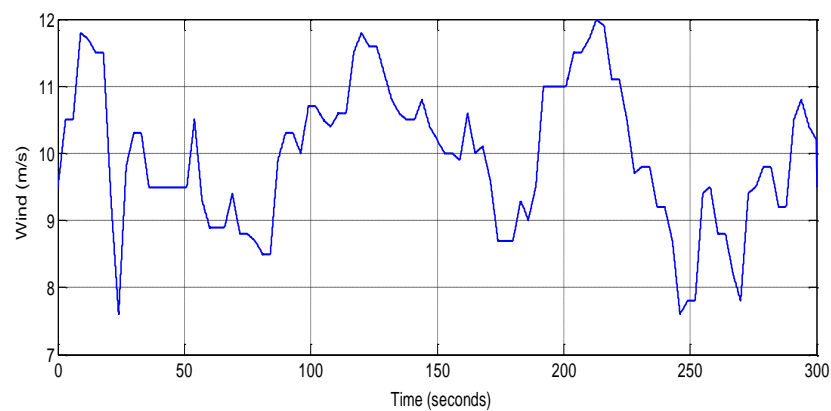

Fig .8. Wind speed

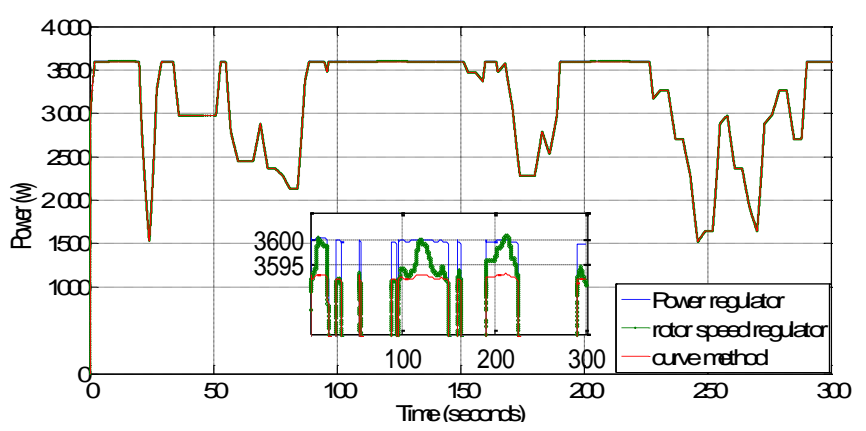

Fig .9. Output power

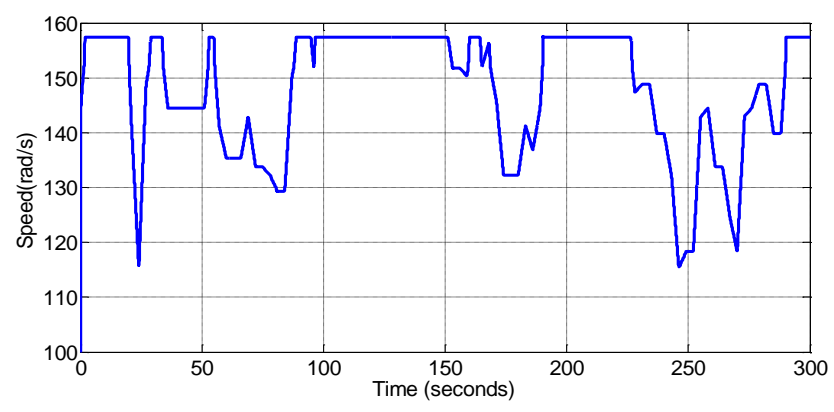

Fig .10. Mechanical speed

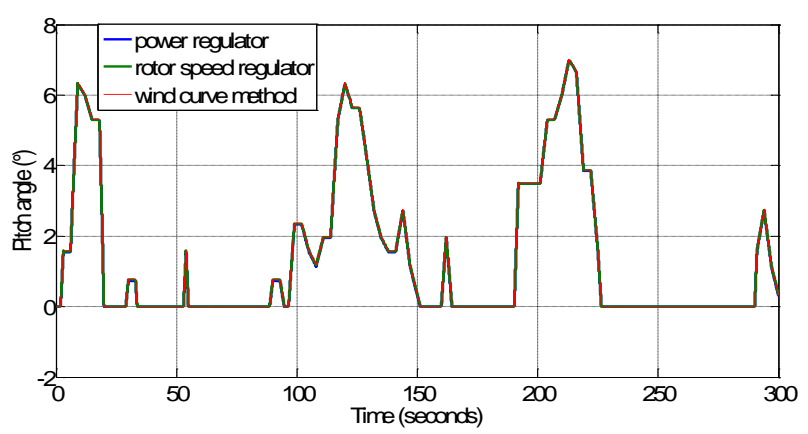

Fig .11. Pitch angle curve

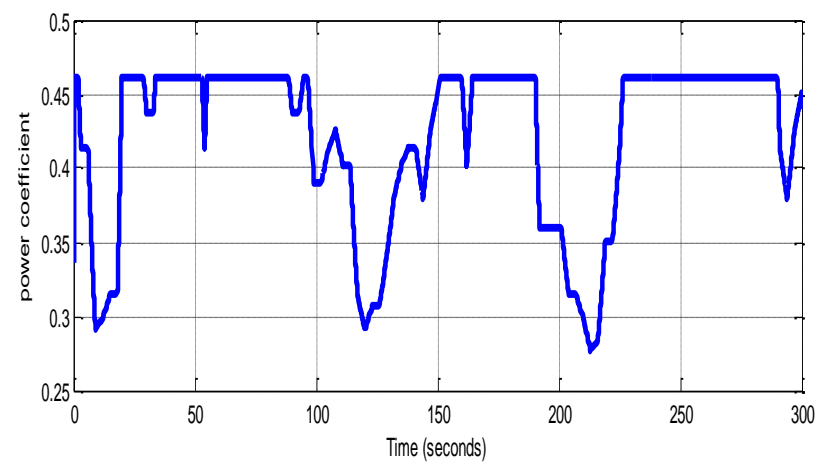

Fig .12. Power Coefficient

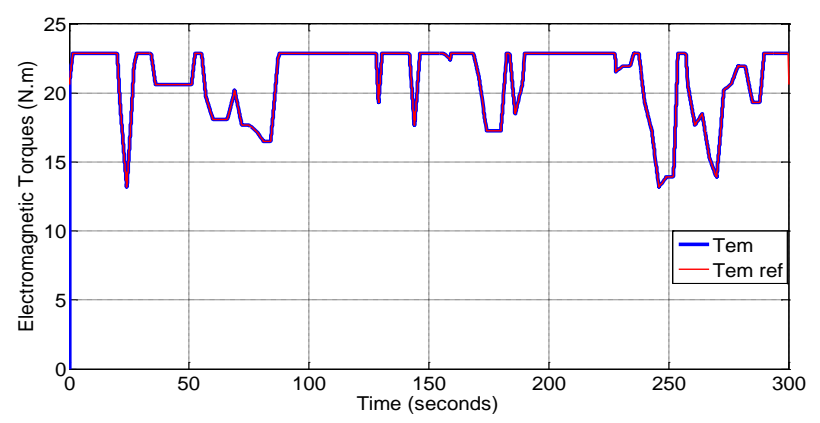

Fig .13. Electromagnetic Torque

The wind turbine is dimensioned to provide a nominal power at a nominal speed of $10 \mathrm{~ms}-1$. Beyond this wind, it is necessary to protect the wind turbine against mechanical failures; therefore, we must limit its speed. This limitation will be obtained by a pitch control. The mechanical speed of the turbine represented in Fig. 10 is obtained next to the variation of the pitch angle illustrated in Fig. 11. The more the pitch angle increases, the more the power coefficient decreases (Fig. 12). The comparisons of different strategies illustrated in the simulation results show that pitch angle control strategy where the generator power is used as the controlling variable has a rapid pitch angle respond to the wind speed variation and minimum power ripples. 
The response of the second strategy where rotor speed is used as the controlling variable has a squared error evaluated of 0.79 and the error of the

Response obtained next to the wind curve pitch control method is evaluated of 0.95 , these results highlight the robustness of the strategy of the generator power controller.

\section{CONCLUSION}

In order to handle the pitch control in wind turbines, in this paper conventional methods are proposed. In fact, pitch angle control has an effect on the aerodynamic loads which may be controlled by the controller to achieve lower torque peak as well as lower fatigue loads. The simulation results show that the power controller has lower torque peak and lower power peak.

\section{REFERENCES}

[1] Lior, N. (2008) Energy Resources and Use: The Present Situation and Possible Paths to the Future, Energy, 33(6): pp. 842-57.

[2] Lund, P.D, (2009) Effects of Energy Policies on Industry Expansion in Renewable Energy, Renew Energy, 34(1): pp. 53-64.

[3] Østergaard P.A, (2009) Reviewing Optimization Criteria for Energy Systems Analyses of Renewable Energy Integration, Energy, 34(9):1236-45G.

[4] Wen, J., Zheng, Y., Donghan, F. (2009) A Review On Reliability Assessment for Wind Power, Renew Sustain Energy Review, 13(9): pp. 2485-94.

[5] Chowdhury M.A, Hosseinzadeh N, Shen W.X. (2012) Smoothing Wind Power Fluctuations by Fuzzy Logic Pitch Angle Controller. Renewable Energy; 38: pp. 224-233.

[6] Pao, L. Y., and Johnson, K. E. (2011) Control of Wind Turbines: Approaches, Challenges and Recent Development, IEEE Control Systems Magazine April.

[7] Duong, M.Q., Grimaccia, F., Leva, S.,
Mussetta, M., and Ogliari, E. (2014) Pitch Angle Control Using Hybrid Controller for All Operating Regions Of SCIG Wind Turbine System. Renewable Energy, 70:pp. 197- 203.

[8] Suryanarayanan, S. (2005) A. Dixit, Control of Large Wind Turbines: Review and Suggested Approach to Multivariable Design, Proc. of the American Control Conference, Portland, USA, pp. 686-690.

[9] Firdaus, A. A. (2014) Design and Simulation of Neural Network Predictive Controller PitchAngle in Permanent Magnetic Synchronous Generator Wind Turbine Variable Pitch System. In Information Technology, Computer and Electrical Engineering (ICITACEE), 1st International Conference on (pp. 346-350). IEEE.

[10] Yuan, X., \& Li, Y. (2013) Control of Variable Pitch and Variable Speed Direct- Drive Wind Turbines in Weak Grid Systems with Active Power Balance. IET Renewable Power Generation, 8(2), pp. 119-131.

[11] Wang, Z., Cai, C., \& Jia, K. (2013, July). Neural Network Adaptive Control for Constant Output Power of Variable Pitch Wind Turbine. In Vehicular Electronics and Safety (ICVES), 2013 IEEE International Conference on (pp. 165-170). IEEE.

[12] Muhando, E.B., Senjyua, T., Urasakia, N., Yonaa, A. K, and Funabashi, T. (2007) Gain Scheduling Control of Variable Speed WTG Under Widely Varying Turbulence Loading, Renew Energy;32(14): p.2407

[13] Courtecuisse,V. Supervision D'une Centrale Multisources a Base D'éoliennes et de Stockage D'énergie Connectée au Réseau Electrique.

[14] Leclercq, L. (2004) Apport du Stockage Inertiel Associé a des Eoliennes dans un Réseau Electrique en Vue D'assurer des Services Systèmes Thèse de Doctorat : Génie Electrique : Université des Sciences et Technologies de Lille, Villeneuve d'Asq, , 171 p, n॰3563. 
[15] Melício R, Mendes, V.M.F., Catalão J.S. (2011) Transient Analysis of Variable- Speed Wind Turbines at Wind Speed Disturbances and a Pitch Control Malfunction, Applied Energy; vol.88; pp.1322-1330

[16] Rodriguez-Amenedo, J. L., Arnalte, S. et Burgos, J. C. Automatic Generation Control of Wind Farm with Variable Speed Wind.

[17] Kesraoui M, Korichi N, Belkadi A. (2011) Maximum Power Point Tracker of Wind Energy Conversion System. Renewable Energy; 36: pp. 2655-2662.

[18] Xing G. (2011) Research on Application of Fuzzy PID in Collective Pitch Control System. Control, Automation and Systems
Engineering (CASE): pp. 1-4.

\section{APPENDIX}

- Wind turbine

Dry friction torque : $\mathrm{Cs}=953 \mathrm{Nm}$

Number of blades : 3

Viscous friction coefficient $: f=10-3 N$.m.s.rad-1

Total inertia of the mechanical transmission: $\mathrm{J}=99$ 10-4 kg.m2

\section{- PMSG}

Nominal power: $\mathrm{Pn}=3.6 \mathrm{~kW}$

Number of pole pairs: $p=4$

Self-inductance: $\mathrm{Ls}=15.1 \mathrm{mH}$

Permanent magnetic flux: $\Phi \mathrm{a}=0.5 \mathrm{Nm} / \mathrm{A}$

Stator resistance: $\mathrm{Rs}=0.82 \Omega$ 